NASA Technical Memorandum 107156

(i) 22

$=20$ ?

AIAA-96-1104

\title{
CW Interference Effects on High Data Rate Transmission Through the ACTS Wideband Channel
}

Robert J. Kerczewski, Duc H. Ngo, Quang K. Tran, Diepchi T. Tran, and John Yu Lewis Research Center

Cleveland, Ohio

Brian A. Kachmar

Analex Corporation

Brook Park, Ohio

James S. Svoboda

NYMA, Inc.

Brook Park, Ohio

Prepared for the

16th International Communications Satellite Systems Conference cosponsored by AIAA, CASI, AAAF, DGLR, and IEICE

Washington, D.C., February 25-28, 1996

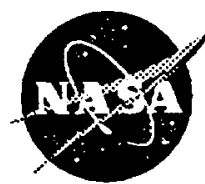

National Aeronautics and

Space Administration 


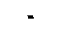




\title{
CW INTERFERENCE EFFECTS ON HIGH DATA RATE TRANSMISSION THROUGH THE ACTS WIDEBAND CHANNEL
}

\author{
Robert J. Kerczewski, Duc H. Ngo, Quang K. Tran, Diepchi T. Tran, and John Yu \\ NASA Lewis Research Center \\ Cleveland, Ohio \\ Brian A. Kachmar \\ ANALEX Corporation \\ Brook Park, Ohio \\ and \\ James S. Svoboda \\ Nyma Technology Inc. \\ Cleveland, Ohio
}

\begin{abstract}
Satellite communications channels are susceptible to various sources of interference. Wideband channels have a proportionally greater probability of receiving interference than narrowband channels. NASA's Advanced Communications Technology Satellite (ACTS) includes a $900 \mathrm{MHZ}$ bandwidth hardlimiting transponder which has provided an opportunity for the study of interference effects on wideband channels. A series of interference tests using two independent ACTS ground terminals measured the effects of unmodulated continuous-wave (CW) uplink interference on the bit-error rate of a $220 \mathrm{Mbps}$ digitally modulated carrier. These results indicate the susceptibility of high data rate transmissions to $\mathrm{CW}$ interference and are compared to results obtained with a laboratory hardware-based system simulation and a computer simulation.
\end{abstract}

\section{Introduction}

The ACTS wideband transponder was designed primarily for high data rate use - $220 \mathrm{Mbps}$ up to $622 \mathrm{Mbps}$. The primary digital modulation format originally intended for use with ACTS is minimum shift keying (MSK), a continuous-phase modulation which suffers no significant sidelobe regrowth when passed through a hardlimiter such as the ACTS wideband transponder. However, during the on-going ACTS experiment period, experimenters have successfully transmitted data through the ACTS wideband channel at rates as low as $2.4 \mathrm{kbps}, \mathrm{Tl}$ (1.544 Mbps), 48, 110 and $220 \mathrm{Mbps}$, and up through $622 \mathrm{Mbps}$. This variety of data rates indicates the utility of the ACTS wideband transponder. Although it may not be particularly profitable to operate a transponder channel in this manner, for the purposes of an experiment program it has proved very successful in providing a platform for a diverse set of experimenters.

The purpose of NASA Lewis's ongoing investigations into the effects of $\mathrm{CW}$ interference is to evaluate the performance of the MSK modulation scheme and the performance of the ACTS wideband hardlimiting transponder in transmitting MSK modulation. The susceptibility of MSK and the ACTS transponder to uplink interference has implications for future satellite systems in terms of interferenoe protection ratios, satellite spacing, and antenna sidelobe performance, as well as for the utility of MSK modulation use in satellite links.

Prior to the launch of ACTS, a laboratory hardware testbed was developed to evaluate satellite and ground terminal components and perform system level experiments. This testbed was used to perform CW interference simulations during 1988-89. More recently (1995), computer simulations using the Signal Processing Worksystem (SPW) from Cadence Design Systems, Inc., were performed. With the launch of ACTS in September, 1993, and the development of two experiment ground terminals by NASA Lewis, it became possible to perform the most accurate experiments using a real flight system and interference scenarios identical to what would be encountered in operational satellite systems. These experiments were 
completed in 1995. Three sets of results, from the laboratory experiments, the computer simulation, and the ACTS experiments are presented and compared below.

\section{The Experimental Procedures}

An implementation of MSK known as Serial MSK (SMSK) was used for all of the experiments and simulations. For the laboratory and ACTS experiments, identical SMSK modems, operating at $220 \mathrm{Mbps}$ were used'. For the computer simulation, software models of an SMSK modulator and demodulator were developed?. The SMSK modulation proctuces a signal spectrum which has a main spectral lobe width of 1.5 times the data rate, or $330 \mathrm{MHZ}$ for a $220 \mathrm{Mbps}$ signal. Fig 1 is a spectrum analyzer plot of the SMSK modulator output with a pseudorandom data input.

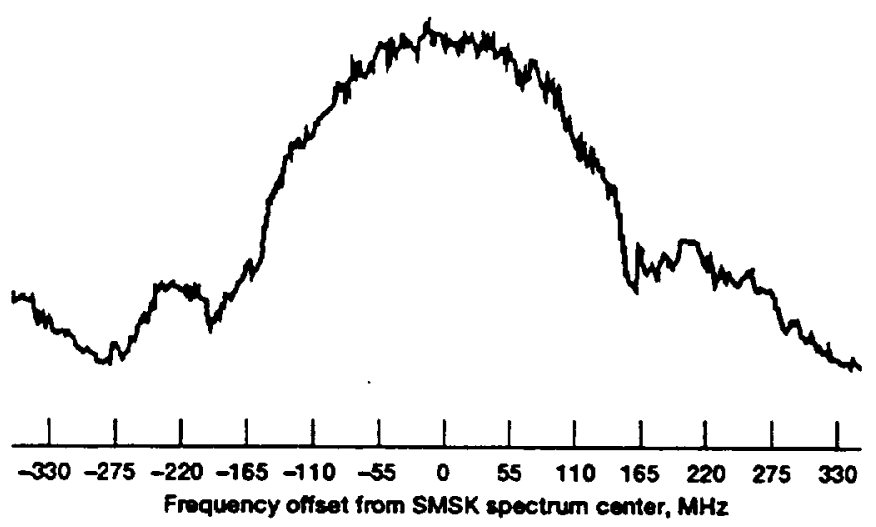

Figure 1 - 220 Mbpe SMSK modulator output spectrum.

$\mathrm{CW}$ interference was introduced into the data channel at various frequencies and power levels. The interferer was introduced at the ground terminal IF stage for the laboratory experiments (due to equipment limitations), and at the satellite receiver for the computer simulations. For the ACTS experiments, the interferer and desired signals were transmitted to the satellite receive antenna from independent transmitting terminals. In all cases, frequency was varied in increments of $1 / R R(R=$ data rate). For $220 \mathrm{Mbps}$, this corresponds to $55 \mathrm{MHZ}$. The $\mathrm{x}$-axis in Fig. 1 indicates the placement of interferers relative to the modulation spectrum. The edge of the main spectral lobe is located at $\pm \% R$. For the laboratory experiments, $C W$ interference was introduce from $-R$ to $+R$ and for the simulations the interference ranged from $-1.5 R$ to $+1.5 R$. For the ACTS experiments, the placement of the signal within the transponder band allowed interference from $-2 R$ to $+R$
Bit-error rate (BER) was used to determine the digital signal degradition due to interference in all cases. For the laboratory and ACTS experiments, a psecudorandom data sequence was transmitted and errors in the received data detected and counted, using an automated BER and signalto-noise ratio measurement system ${ }^{\text {'s. }}$. The computer simulation used a semi-analytical technique to estimate $\mathrm{BER}^{2}$. The degredation is measured in terms of energyper-bit to noiso-power-density ratio $\left(E_{\sqrt{ }} N_{2}\right)$ degradation (in dB) compared to the theoretical MSK BER curve as follows. For BER curves developed as a function of $E_{\sqrt{ }} / N_{\text {}}$. in the laboratory experiments and computer simulations, the degradation is measured by subtracting the $E_{\sqrt{ }} N_{0}$ at a BER of $10^{-6}$ for the theoretical curve $(10.5 \mathrm{~dB})$ from the $E_{0} / N_{\text {, a }}$ a $B E R$ of $10^{-6}$ for the measured curve. For the ACTS experiments, a single BER measurement is produced, rather than an entire curve. This result is plotted onto the theoretical curve, and the corresponding $E_{1} N_{0}$ is subtracted from the theoretical curve $E_{0} N_{0}$ at a BER of either $10^{-6}$ or $10^{-9}$, depending on the experiment. All of the results are presented below in terms of BER degradation as a function of interferer relative frequency. Note that this degradation will include modem implementation losses and system losses which occur without any interference present for the laboratory experiments and computer simulations. The magnitude of these implementation losses are indicated by the least degraded sets of data points on the corresponding curves presented below. The ACTS experiments results do not include the implementation and system losses because the data points are compared to a single point along the theoretical curve.

\section{Laboratcry Experiments}

The results for the laboratory experiments have been previously reported ${ }^{35,}$, so only a brief review will be given here. The Advanced Space Communications Laboratory's satellite systern simulator and testbed was used to perform these experiments. The testbed consists of a hardwarebased $\mathrm{Ka}$-Band transponder, ground terminal up/down converters, digital ground terminal, and automated experiment control and monitoring'. Complete characterization of the system has been performod. The most significant aspects of the transponder performance are the $2.5 \mathrm{GHz}$ bandwidth of the transponder channel and the non-linearity of the output transmitter, which is operated at saturation. The transponder power characteristic thus approximates a soft-limiter, and is the major difference in transponder characteristics between the laboratory experiments and the computer simulations and ACTS experiments. 


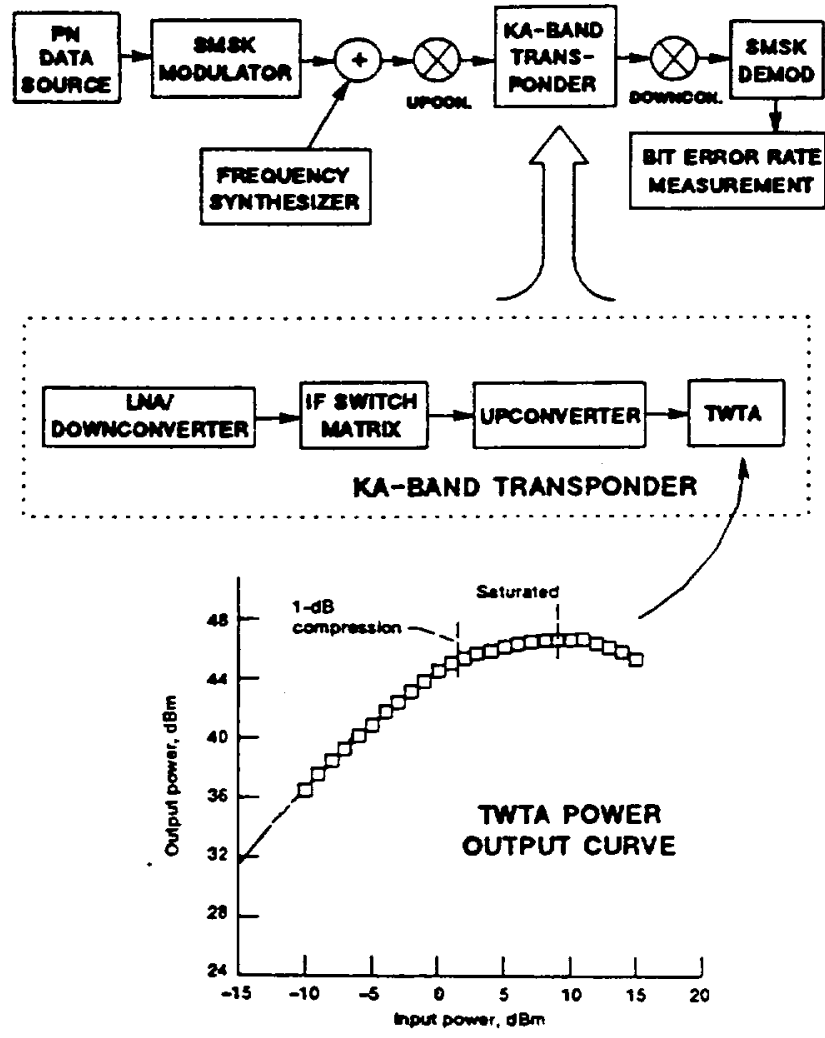

Figure 2 - Experiment setup for the laboratory $\mathbf{C W}$ interference experiments.

Figure 2 shows a block diagram of the test setup and a plot of the measured TWTA power output curve. In the laboratory experiments, the interference is introduced at the input to the ground terminal upconverter. In comparison to the ACTS experiments, frequency conversion occurring in the upconverter presents an additional source of intermodulation between the interferer and desired signal. However, several frequency conversions occurring in the satellite transponder and ground terminal receiver make this additional effect insignificant. Filtering in the upconverter subsystem limits the range of $\mathrm{CW}$ interferer frequencies to $\pm \mathbf{R}$.

The SMSK modulator was operated in a continuous mode at a $220 \mathrm{Mbps}$ throughput rate for these tests. The $\mathrm{CW}$ interference was measured relative to the total desired signal power at the interference insertion points. The interference level was varied from $0 \mathrm{~dB}$ to $-30 \mathrm{~dB}$. Results are shown in Fig. 3.

For interferer powers above $-10 \mathrm{~dB}$, loss of carrier

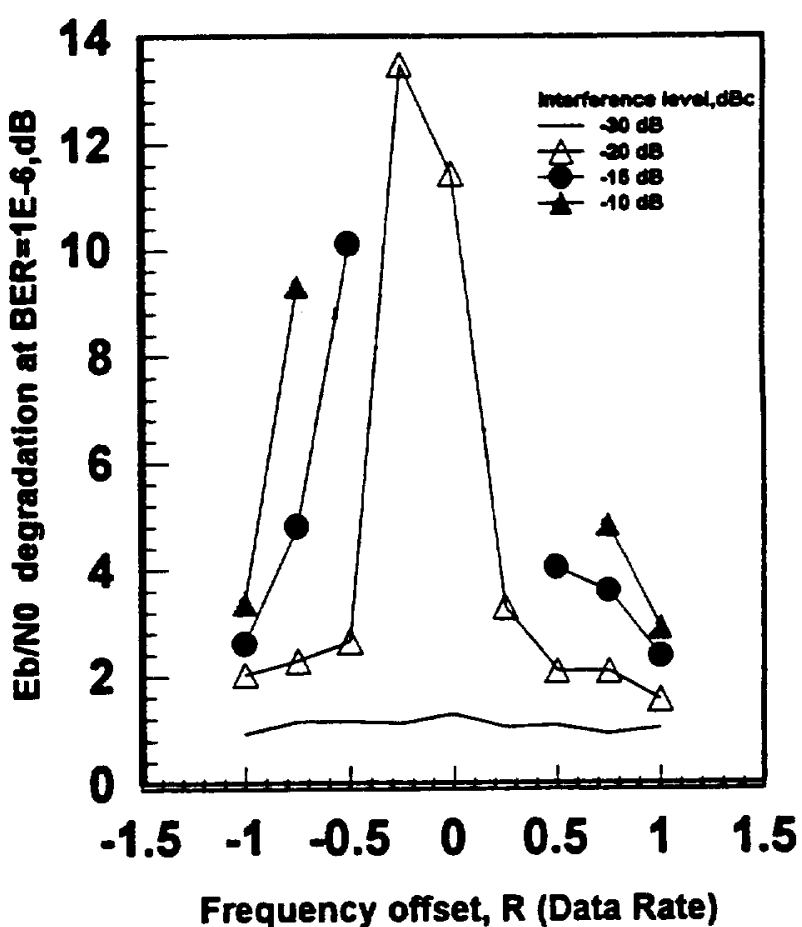

Figure 3 - BER degradation as a function of interferer relative power level and frequency for the laboratory experiments.

synchronization was experienced by the demodulator, resulting in a BER of 0.5 , when interferers were located within the spectral bandwidth. At interferer levels of -10 $\mathrm{dB}$ and $-15 \mathrm{~dB}$, loss of carrier cocurred when the interferer was located near the center of the signal spectrum, with severe BER degradation occurring when the interferers were located near the edge of the spectrum. At $-20 \mathrm{~dB}$ interference level the carrier synchronization was maintained throughout the spectrum, but with severe degradation near the center. Interferer levels of $-30 \mathrm{~dB}$ and below resulted in negligible degradation throughout the spectrum. For all interferer power levels, the degradation decreased to negligible when the interferer was placed outside the moctulated signal spectrum, that is, beyond $\pm 3 / 4 R$.

\section{Computer Simulations}

The computer simulations made use of the Signal Processing Worksystem (SPW) from Cadence Design Systems, Inc. The simulation model was created as shown in Fig. 4. The SMSK modulator and demodulator models were developed based upon the SMSK modems used in the laboratory and ACTS experiments ${ }^{1,2}$. The model for the 


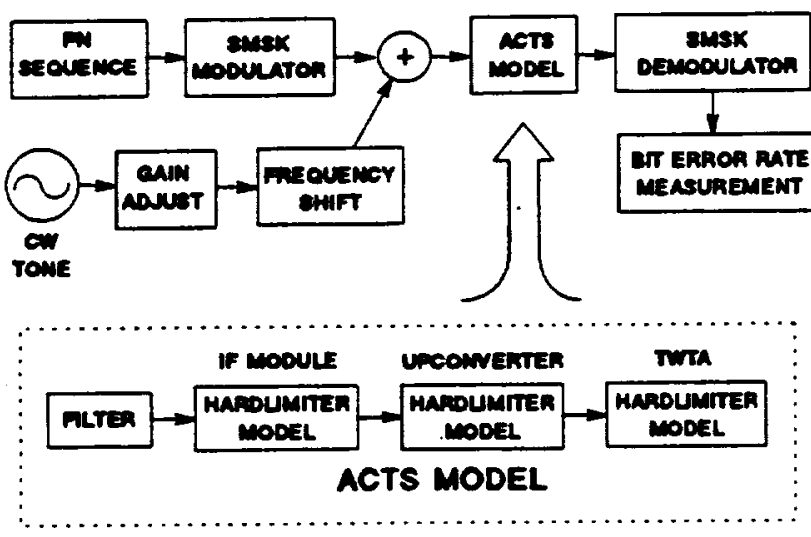

Figure 4 - Diagram of the simulation model for the computer aimulations.

ACTS transponder includes bandpass filtering and three cascaded hardlimiter elements. The hardlimiting elements represent three cascaded subsystems within the ACTS transponder which contain hardlimiting amplifiers. The models consists of three TWT lookup tables consisting of AM/AM and AMPM characteristics obtained from ACTS hardware tosts. The simulation made use of semi-analytical techniques to develop a BER as a function of $E_{0} N_{0}$ curve for each interference scenario. The $\mathrm{CW}$ interferer was added to the modulated sigaal at the ACTS transponder input; the interferer power level relative to the modulated signal was measured at this input point. Interferer relative power levels of $0 \mathrm{~dB}$ to $-10 \mathrm{~dB}$ were simulated. Results are shown in Fig. 5.

The symmetry of the computer model results in a symmetric simulation result, as Fig. 5 shows. The degradation is much less severe than for the laboratory experiments. Only for a $0 \mathrm{~dB} \mathrm{CW}$ interferer place at the center of the modulated signal spectrum did loss of carrier synchronization occur. For all other cases, the degradation was limited to $5.3 \mathrm{~dB}$ or less. $\mathrm{CW}$ interference of $-5 \mathrm{~dB}$ caused minor degradation near the center of the modulated spectrum, while $-10 \mathrm{~dB}$ resulted in negligible degradation across the entire spectrum. Note also that for the $0 \mathrm{~dB}$ interference, some BER degradation cocurred for interferers placed outside the modulated spectrum (beyond $t \% / \mathrm{R}$ ).

\section{ACTS Experiments}

The ACTS satellite is an experimental communications satellite developed under the direction of NASA Lewis and launched aboerd the Space Shuttle on September 12, 1993. Following system checkout, the ACTS Experiments

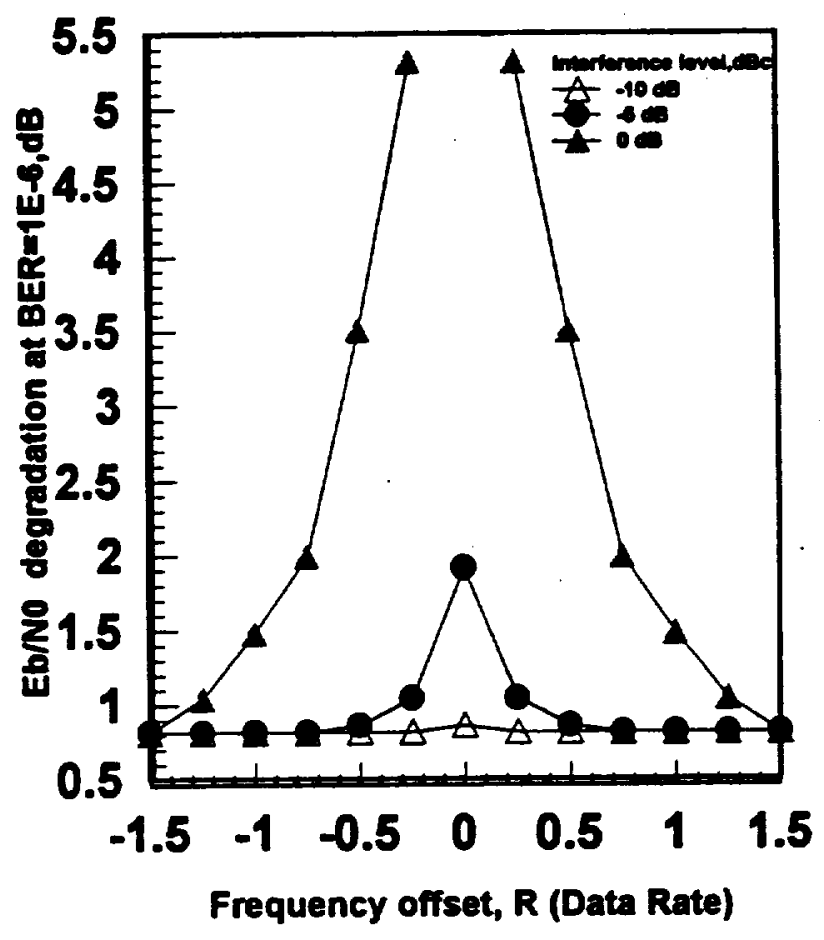

Figure 5 - BER degradation a a function of interferer relative power level and frequency for the computer simulations.

Program began in November, 1993, and continues at the present time. Two experiment terminals developed by NASA and located at NASA Lewis were used for the CW interference experiments. These terminals are called HBRLET (High Burst Rate Link Evaluation Terminal) and INTEX (Interference Experiment Terminal). Both terminals were developed for high data rate experiments with ACTS, and are of similar design. Both have 40 Watt transmitters; the HBR-LET uses a 4.7 meter reflector antenna while the DNTEX uses a 2.44 meter reflector. Both terminals reside within the same ACTS antenna beam (the Cleveland fixed spot beam).

The experimental setup diagram is shown in Fig. 6. The HBR-LET terminal produces the desired modulated signal, operating in a loopback mode through the ACTS satellite. The INTEX terminal provides a CW interferer which is added to the link at the ACTS receive antenna The experiment control computers, located in the HBR-LET control room, operate the HBR-LET terminal and monitor BER performance, and also remotely control the INTEX terminal, varying the frequency and power level of the uplink CW interferer. Access to ACTS telemetry is also available. 
The HBR-LET digital ground terminal contains an SMSK modem identical to that used in the laboratory experiments. The ground terminal has been designed, however, for TDMA operation, and thus produces a bursted modulated signal rather than a continuous modulated signal as for the digital ground terminal used in the laboratory tests. This has no significant implications for the results, but it did require longer measurement times for the ACTS experiments in order to obtain statistically significant measurements. The modem burst rate was variable, allowing data throughput rates of 13.8, 27.5, 55, 110, and $200 \mathrm{Mbps}$. CW interference experiments were performed at all of these rates. But significant differences in results based on data throughput rate were not observed, so only a subset of the these results will be presented.

The link budgets for the HBR-LET terminal show that the downlink path has considerably higher margin than the uplink path. This allowed the overall link BER to be controlled by varying the uplink transmit power. During periods of link attenuation due to rain and heavy clouds, the link BER could be accurately maintained by increasing the uplink power. ACTS telemetry data included the received power (measured prior to the hardlimiting portions of the transponder), hence, the link BER was maintained by keeping the ACTS received power constant. Only during heavy rainstorms, or during rapidly fluctuating conditions, was it not possible to continue the experiment. The interference experiments were conducted for two link operating points. One, called the standard power level, has the link operating nearly error-free, although not at maximum transmit power. Tests indicated that the BER at standard power was about $10^{-11}$. The second operating point was called the $10^{-6}$ power level, in which the uplink transmit power is adjusted to maintain a BER of $10^{-6}$, without interference. $\mathrm{CW}$ relative interference levels were set over a range of 0 to $-15 \mathrm{~dB}$.

The following procedure was followed for each BER measurement for the ACTS CW interference experiments. For each point the link was established at standard power level or $10^{-6}$ power level by observing the ACTS receive power telemetry with a continuous modulated signal. The un-interfered $B E R$ was verified with a BER measurement of one minute. A zero-error condition was required for the standard power level. For the $10^{-6}$ power level, the BER was required to be within the range $9 \times 10^{-5}$ to $1.1 \times 10^{-6}$.

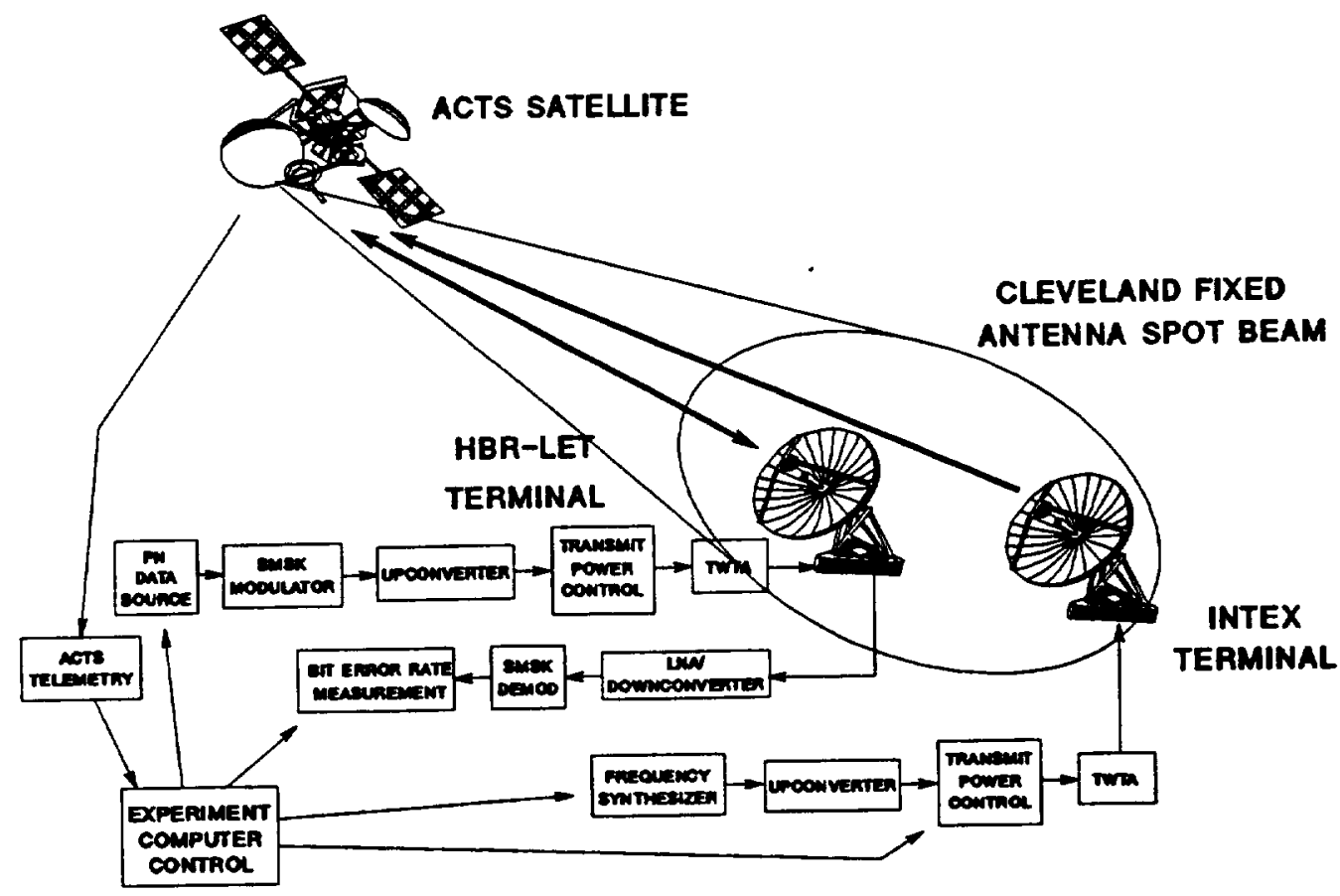

Figure 6 - Experimental setup for the ACTS CW interference experiments. 
During rain and cloud conditions this was extremely difficult to maintain. Once the modulated signal power was established, the signal was turned off and the DNTEX CW interferer was transmitted. Again; ACTS telemetry was used to set the $C W$ interferer power level, relative to the modulated signal. Once the $\mathrm{CW}$ transmission was set, it was turned of while the modulated signal BER was verified again, prior to the interference test. After all power levels were thus verified, the modulated signal and interferer were transmitted simultaneously and the BER of the modulated signal was measured. During the longer measurements, ACTS fade beacon power and ACTS telemetry data were monitored to ensure that no significant link variations were occurring.

Figs. 7-9 show the results of three $\mathrm{CW}$ interference experiments. In Fig. 7, the data throughput rate was 55 Mbps (a burst duty cycle of 0.25 ), and the link operating point was the standard power level.. This experimental condition most closely resembles the laboratory experiment and computer simulation conditions, in that the interferer was combined with the modulated signal and passed through the transponder at a relatively high $E_{0} / N_{0}$. In Figs. 8 and 9 the link operating point was the

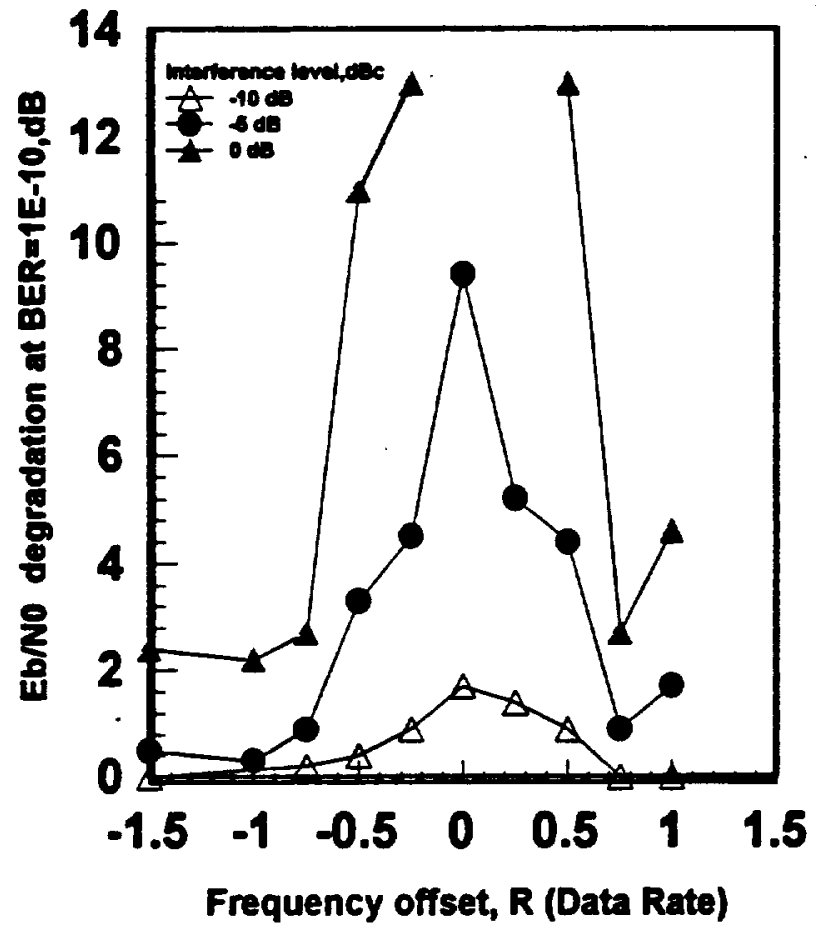

Figure 7 - BER degradation as a function of interferer relattve power level and frequency for the ACIS experiments, throughput data rate of $55 \mathrm{Mbps}$ at the standard power level.
$10^{-6}$ power level. In Fig. 8 the data throughput rate wes $55 \mathrm{Mbps}$ and in Fig. 9 it was $110 \mathrm{Mbps}$. For the 55 $\mathrm{Mbps}$, stendard power level case (Fig 7), the CW interfecer near the center of the spectrum, at $0 \mathrm{~dB}$ relative power level, resulted in carrier synchronization loss. At other power levels and at frequencies away from the center, carrier synchronization was maintained At $-5 \mathrm{~dB}$ interferer power level, severe degradation occurs near the center of the spectrum. At -10 dB, some minor degradation at the center of the spectrum can be observed. Below -10 dB, the BER degradation was negligible seross the entire spectrum (the dat for CW interference below $-10 \mathrm{~dB}$ is not plotted in Figs. 7-9 to maintain clarity in the plot). Note also that some BER degradation occurred for $\mathrm{CW}$ interferers located outside the modulated spectrum (beyond $12 / 4 R$ ).

The $10^{6}$ power level, $55 \mathrm{Mbps}$ throughput data rate experiments (Fig. 8), indicate that the CW interference causes more degradation than at the standard power level operating point. The $\mathrm{CW}$ interferer is interacting with a

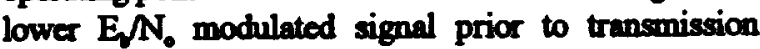
through the transponder, and the resulting degradation is approximately 1 to $1.5 \mathrm{~dB}$ higher across the spoctrum.

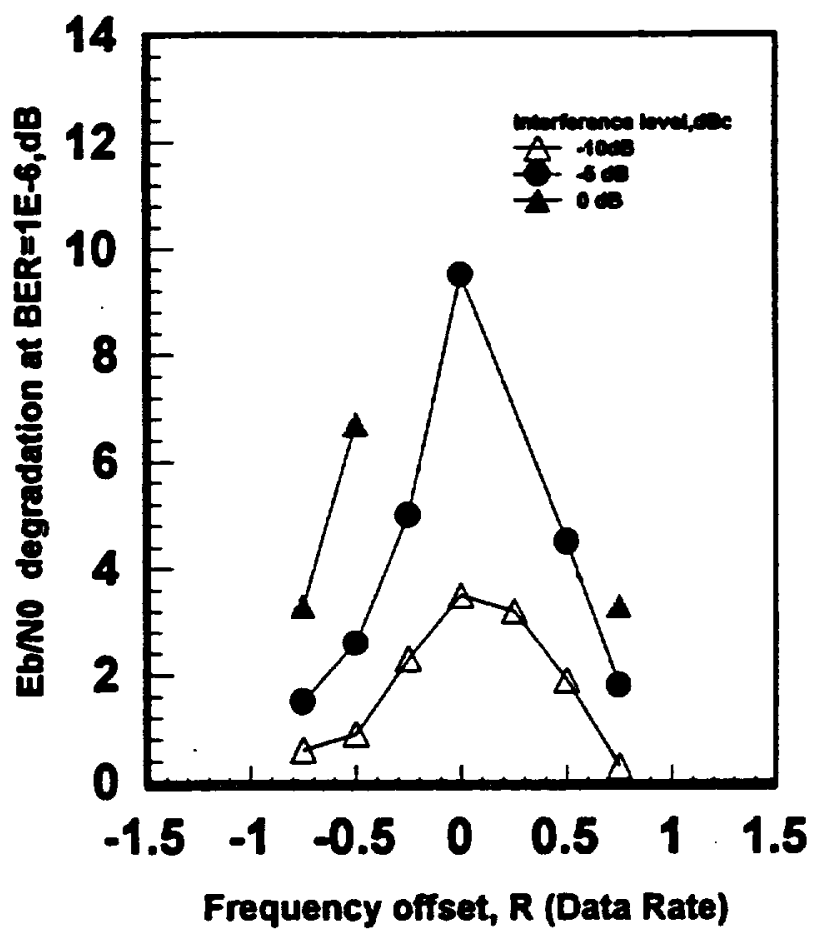

Figure 8 - BER degradation as a function of interferer relative power level and frequency for the ACTS experiments, throughput data rate of $55 \mathrm{Mbps}$ at the $10^{\circ}$ power level. 


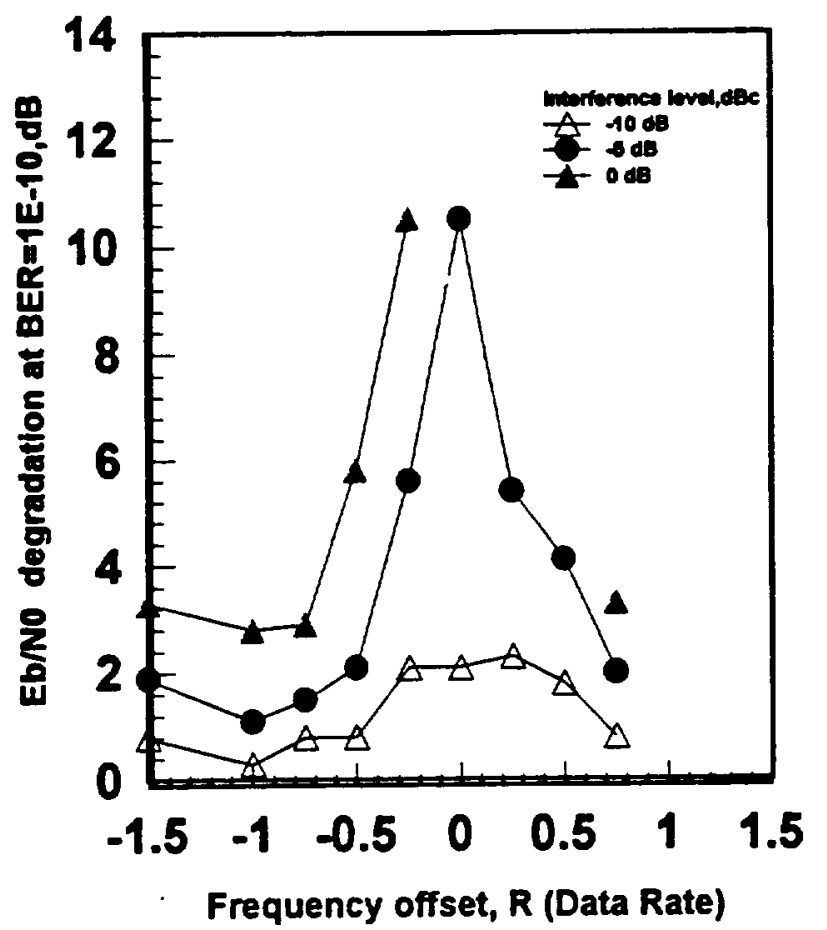

Figure 9 - BER degradation as a function of interferer relative power level and frequency for the ACTS experiments, throughput data rate of 110 Mbps at the $10^{-6}$ power level

The $0 \mathrm{~dB}$ interferer causes carrier synchronization loss over a larger portion of the spectrum.

The $10^{-6}$ power level, $110 \mathrm{Mbps}$ throughput data rate experiment results (Fig. 9) lie between the $55 \mathrm{Mbps}$ standard power level and $55 \mathrm{Mbps} 10^{-6}$ power level results. Although the BER degradation in this case is a little higher than for the $55 \mathrm{Mbps} 10^{-6}$ power level case, several points measured for $110 \mathrm{Mbps}$ at the standard level indicate degradation comparable to the $55 \mathrm{Mbps}$ standard power level case (data not shown). Thus, the increased degradation may be related to the interaction of higher $\mathrm{Eb} / \mathrm{No}$ and higher burst rate duty cycle.

\section{Comparison of Results}

The ACTS CW interference experiment results are obviously the best indicator of $\mathrm{CW}$ interference effects because they are based on a real, operational satellite link In comparing the experimental conditions which are the closest for the laboratory and ACTS experiments and the computer simulation, we find that the computer simulation gives an excellent approximation of the real ACTS link results. The ACTS model implemented in the computer simulation appears to be a very accurate rendition of the operational ACTS transponder. The laboratory experiments greatly overestimate the effects of CW interference compared to the ACTS case. The labcratary simulated SMSK Ka-band channel is about 15 $\mathrm{dB}$ more sensitive to $\mathrm{CW}$ interference than the ACTS SMSK channel. This is due to the difference between the laboratory Ka-band transponder model and the ACTS transponder, the primary difference appears to be the soft-limiting characteristic of the laboratory model compared to the cascaded hardlimiter characteristic of the ACTS transponder.

\section{Summary}

Experiments performed with the ACTS satellite and two independent ground terminals have been used to quantify the sensitivity of the ACTS wideband, hardlimiting channel to CW interference in the transmission of a 220 Mbps SMSK signal. The results show that the ACTS SMSK channel is severely degraded by interferers at relative power levels of $-5 \mathrm{~dB}$ and above placed near the center of the modulated spectrum, and moderately degraded at these power levels for interferers located at the outer edges and outside of the spectrum. Interferer power levels of $-10 \mathrm{~dB}$ cause small amounts of degradation near the center of the spectrum. Below -10 $\mathrm{dB}$ interference effects are negligible.

A computer simulation using an ACTS transponder model consisting of a filter and three cascaded hardlimiter models, based upon ACTS hardware test data, gives an accurate simulation of the actual ACTS experimental results. A laboratory-based hardware simulation, using a Ka-band transponder with a soft-limiter characteristic as opposed to the hardlimiter characteristics of the ACTS transponder, overestimated the CW interference sensitivity of the ACTS SMSK channel by about $15 \mathrm{~dB}$. 


\section{References}

1. Ziemer, R. E., and Ryan, C. R, "Minimum Shift Keyed Modem Implementation for High Data Rates", IEEE Communications Magazine, Vol. 21, No. 7, Oct, 1983, pp. 28-37.

2. Yu, J., "Cochannel and Adjacent Channel Interference in Nonlinear Minimum-ShiftKeyed Satellite System", NASA Technical Memorandum 106834.

3. Kerczewski, R. J., Daugherty, E. S., and Kramarchuk, I., "Autmoated Measurement of the Bit-Error Rate as a Function of Signal-toNoise Ratio for Microwave Communication Ssytems", 29th Automatic RF Techniques Group Conference, June, 1987. (NASA Technical Memorandum 89898.

4. Shalkhauser, M. J., and Budinger, J. M. "Digitally Modulated Bit-Error Rate Measurement Ssytem for Microwave Component Evaluation", NASA Technical Paper 2912, 1989.

5. Kerczewski, R. J., and Fujikawe, G., "Interference Susceptibility Measurements for an MSK Satellite Commumication Link", 14th AIAA International Communication Satellite Systems Conference, March, 1992.

6. Fujikaws, G., and Kerczewski, R. J., "Phase I Final Report of the SITE Project: Continuous Data BER Testing", NASA Technical Paper 3279, September, 1992.

7. Kerczewski, R J., Svoboda, J. S., and Kachmar, B. A., "Facility for the Evaluation of Space Communications and Related Systems". 41st International Instrumentation Symposium, May, 1995. NASA Technical Memorandum 106904.

8. Kerczewsik, R. J., and Fujikawa, G., "Performance Measurements for a LaboratorySimulated $30 / 20 \mathrm{GHz}$ Communication Satellite Transponder", 13th AIAA International Communication Satellite Systems Conference, March, 1990.

9. Gotney, R. T., and Gargione, F, “ACTS - New Services for Communications", Satellite Communications, September, 1994.

10. Lowry, P.A, "ACTS System Handbook", NASA TM 101490.

11. Proceedings of the ACTS Results Conference, NASA Lewis Reseanch Cetner, Cleveland, $\mathrm{OH}$, September 11-13, 1995. 
Public reporting burden tor this collection of information is estimated to average 1 hour per response, including the time lor reviewing instructions, seanching existing data sources, Public repont buintaining the data needed, and completing and reviewing the collection of information. Send comments regarding this burden estimate or any other aspect of this collection of information, including suggestions for reducing this burden. 10 Washington Headquarters Services, Directorate for Information Operations and Reports. 2215 Jetlo Davis Hiatsy, Suin 1204, Arlington, VA 22202-4302, and to the Ottice of Managernent and Budget, Papenwork Reduction Projed (0704-0188), Washinglon, DC 20503.
1. AGENCY USE ONLY (Leave blank)
2. REPORT DATE
January 1996
3. REPORT TYPE AND DATES COVEAED
Technical Memorandum

4. TITLE AND SUBTITLE

CW Interference Effects on High Data Rate Transmission Through the ACTS Wideband Channel

6. AUTHOR(S)

Robert J. Kerczewski, Duc H. Ngo, Quang K. Tran, Diepchi T. Tran, John Yu, Brian A. Kachmar, and James S. Svoboda

7. PERFORMING ORGANIZATION NAME(S) AND ADDRESS(ES)

TMNG ORGANIZATION REPORT NUMBER

National Aeronautics and Space Administration

Lewis Research Center

Cleveland, Ohio 44135-3191

E-10095

9. SPONSORINGMONITORING AGENCY NAME(S) AND ADDRESS(ES)

10. SPONSORINGMONITORING AGENCY REPORT NUMBER

National Aeronautics and Space Administration

Washington, D.C. 20546-0001

NASA TM-107156

AIAA-96-1104

11. SUPPLEMENTARY NOTES

Prepared for the 16th International Communications Satellite Systems Conference cosponsored by ALAA, CASI, AAAF, DGLR, and IEICE, Washington, D.C., February 25-28, 1996. Robert J. Kerczewsk, Duc H. Ngo, Quang K. Tran, Diepchi T. Tran, and John Yu, NASA Lewis Research Center, Brian A. Kachmar, Analex Corporation, 3001 Aerospace Parkway, Brook Park, Ohio 44142 (work funded by NASA Contract NAS3-25776); James S. Svoboda, NYMA, Inc., 2001 Aerospace Parkway, Brook Park, Ohio 44142 (work funded by NASA Contract NAS3-27186). Responsible person, Robert J. Kerczewski, organization code 5660, (216) 433-3434.

12a. DISTRIBUTIONAVAILABILTTY STATEMENT

12b. DISTAIBUTION CODE

Unclassified - Unlimited

Subject Categories 16 and 32

This publication is available from the NASA Center for Aerospace Information, (301) 621-0390.

13. ABSTRACT (Maximum 200 words)

Satellite communications channels are susceptible to various sources of interference. Wideband channels have a proportionally greater probability of receiving interference than narrowband channels. NASA's Advanced Communications Technology Satellite (ACTS) includes a $900 \mathrm{MHZ}$ bandwidth hardlimiting transponder which has provided an opportunity for the study of interference effects on wideband channels. A series of interference tests using two independent ACTS ground terminals measured the effects of unmodulated continuous-wave $(\mathrm{CW})$ uplink interference on the bit-error rate of a $220 \mathrm{Mbps}$ digitally modulated carrier. These results indicate the susceptibility of high data rate transmissions to $\mathrm{CW}$ interference and are compared to results obtained with a laboratory hardware-based system simulation and a computer simulation.

14. SUBJECT TERMS

Interference; Digital satellite communications; ACTS; Ka band 10

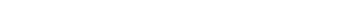

\begin{tabular}{|l|c|}
\hline 17. SECURTY CLASSIFICATION \\
$\begin{array}{c}\text { OF REPORT } \\
\text { Unclassified }\end{array}$ & $\begin{array}{c}\text { 18. SECURITY CLASSIFICATION } \\
\text { OF THIS PAGE } \\
\text { Unclassified }\end{array}$ \\
\hline
\end{tabular}

19. SECURITY CLASSIFICATION OF ABSTRACT Unclassified 


.




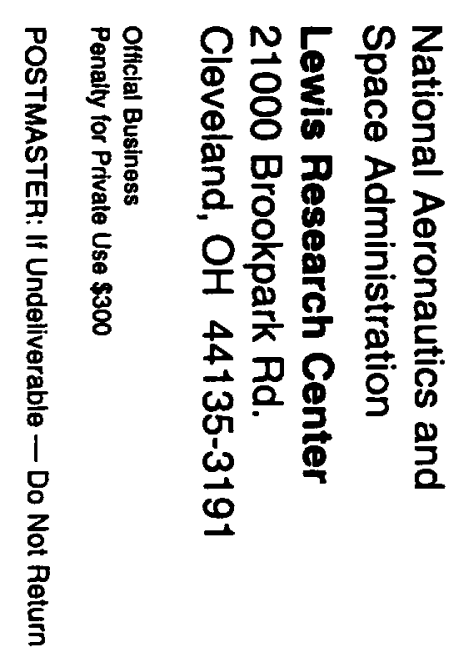

